\title{
The Cognitive Dimension and Course Content Modeling: An Ontological Approach
}

\author{
https://doi.org/10.3991/ijet.v12i05.6854 \\ Kalla. Madhusudhana \\ Teegala Krishna Reddy Engineering College, Hyderabad, India \\ kallamadhul@yahoo.com
}

\begin{abstract}
The recent advances in web-based educational technology, is providing diverse needs of e-learner and revolutionized the process of learning. However, how to enrich the student's understandability and stimulate the learning behavior towards cognitive learning beyond simple lookup is still remaining as open research issue. To facilitate the effective learning process the technology has numerous ways of providing pedagogical assistance. The course content description based on the dimensions of psychological factors and Bloom's taxonomy can help in presenting course material so as to reduce cognitive load and to influence the effective learning style. This paper examines various cognitive strategies and resource description metadata in a course-based learning environment. Finally, the researcher proposed an ontology-based metadata for modeling the course contents of web-based learning environment that supports cognitive prerequisites of the learner.
\end{abstract}

Keywords-Cognitive learning, Pedagogical approach, Ontological framework, Course-based learning environment

\section{Introduction}

Most of the existing research is concentrated on how to build better educational resources, how to deliver the contents as per the preferences and context of the learner. But the mechanism to improve the understanding level and cognitive skills of learner remains as open issue. The content delivery mechanism as per the cognitive needs of learner is currently the focus of research in the educational domain. The cognitive behavioral theory (CBT) can be considered as an important theoretical orientation to understand the student's behavior in web-based learning environments. To learn new concepts it is heavily depending on what the student already knew and his learning behavior.

In an intelligent tutoring system, the conceptual representation of course contents will support the teaching of specific domain knowledge and it will be easier for the student to select an appropriate material [1]. "It is ambivalent to make the learner ambulate among learning concepts with one perspective [2]", but it is the willingness of the learner to navigate based on his skills and learning style. 
The recent web-based developments have led to reconsider the learning style research in adaptive e-learning systems [3], so as to improve the thinking skills of learner. The effective learning strategies and knowledge acquisition process are the mental activities that require the learner's ability and experience, which consists of mainly three activities such as Understanding, Applying, and Analyzing. In technology enhanced learning the integration of pedagogical strategies in an adaptive educational system leads to positive effects on the learning process and performance of the student. The Pedagogical learning activities and assessment process make the student in becoming independent and responsible for their own learning. The main requirement of providing comprehensive support to students learning experience is: the description of learning resources with pedagogical support and cognitive oriented metadata.

The proposed work in this paper provides an expected useful insight into the metadata using an ontological approach. That is designed for the purpose of describing the learning resources with the aim of supporting course-based learning environment. The proposed course content structure ontology synthesizes a number of pedagogical and instructional strategies to facilitate better understanding and improve cognitive skills of the learner. The work presented in this paper focuses mainly on the following aspects:

1. Various issues in learning environment that influence learning process

2. Description of pedagogical strategies and cognitive learning process

3. Ontological framework based on cognitive dimension for modeling the course contents

\section{Cognitive Strategies and E-Learning Environment}

The issues that can be derived from the perspective of self-regulated learning framework associated with the course based learning environment are mainly three interrelated dimensions such as Interface design (Presentation), Query response (Delivery) and Resource description (Storage).

\subsection{Interface design}

The well-designed content presentation approach could greatly influence student's navigation behavior towards investigative learning concerns. "Cognitive load theory has been designed to provide guidelines intended to assist in the presentation of information in a manner that encourage learner activities and optimize intellectual performance [4]". The dimensions of user-interface design should focus on the visual representation of large collection of data to support exploratory search, as exploratory search behavior is part cognitive learning. 


\subsection{Response to query}

The users' learning styles and query reformulation behavior is greatly influenced by their thinking capability. The query reformulation is an important component of web-search behavior, and the user's success in Information Retrieval (IR) depends on queries formulation [5]. The development of improved understanding needs exhaustive searching of information rather than traditional topical search. The extended searching approach of learning environment must return potentially relevant and conceptually neighborhood items rather than a single set of a result in response to a user's query.

\subsection{Resource description}

Although the existing metadata standards for resource description in Intelligent and Adaptive Learning Systems have proven their benefits to e-learners, the effective inferring of cognitive skills and knowledge level of learner remains an open issue. One of the key issues of a cognitive educational environment is the identification of suitable learning resource by search engines and content management system. To support more effective cognitive needs of the learner the user interface technology and the resource description metadata should mainly consider the cognitive psychology and educational objectives of Bloom's taxonomy [6].

\section{Cognitive Learning Process}

Cognitive skill development is the construction of thought processes through exploring, identifying and investigating the characteristics, attributes, relationships, patterns and applicability of learning concept. The distinctions between the cognitive thinking and knowledge actuation process are not always clear-cut. The development of critical thinking skills and reasoning are associated with the prior knowledge and ability (e.g., phonological memory) of learners. As shown in Figure 1, the prior knowledge/background knowledge helps the learner in the mental processes, while understanding the concepts and perceiving Issues and solutions of the problem.

\begin{tabular}{|c|c|c|}
\hline Prior Knowledge & Cognitive Learning style & Cognitive Inference \\
\hline $\begin{array}{l}\text { Declarative } \\
\text { Knowledge } \\
\text { Procedural Knowledge } \\
\text { Contextual } \\
\text { Knowledge }\end{array}$ & $\begin{array}{l}\text { Understandability } \\
\text { Applicability } \\
\text { Analysis }\end{array}$ & $\begin{array}{l}\text { Perceiving Approach- } \\
\text { es } \\
\text { Issues and Solutions } \\
\text { New Ideas }\end{array}$ \\
\hline
\end{tabular}

Fig. 1. Cognitive skill development process

The terms critical thinking and learning style are another key factors that deal with the learner's activity, but the learner's activity can be influenced by means of the 
content presentation environment and self-regulated learning strategies. The effectiveness of an e-learning system depends on the relevancy and presentation of learning content to the learner [7]. The content presentation approach enables the user to explore further information in the context of the current learning topic. In studentcentered learning paradigms, the self-regulated learning processes leads to improvements in student performance [8]. Table 1 shows a sample of the self-regulatory checklist in a cognitive learning process, which contribute to an increased learning skill and to monitor and judging oneself from the specific quality of their work.

Table 1. Self-regulatory checklist in cognitive learning process

\begin{tabular}{|c|l|}
\hline Understandability & $\begin{array}{l}\text { How to reformulate learning topic with known concepts? } \\
\text { What kind of information and strategies need to know? } \\
\text { What are the properties and facts of the topic? } \\
\text { Do I have a clear understanding of what I am learning? } \\
\text { What is the nature of the topic? }\end{array}$ \\
\hline Applicability & $\begin{array}{l}\text { Does the applicability make sense to me? } \\
\text { What are the various constraints, properties, facts and context of application? }\end{array}$ \\
\hline Analysis & $\begin{array}{l}\text { How to decompose and define relationships among various components of } \\
\text { learning concept? } \\
\text { Do I need to make any changes to make it work as per the context and applica- } \\
\text { tion environment? } \\
\text { What works and what does not work? }\end{array}$ \\
\hline
\end{tabular}

\section{Cognitive Dimension and Resource Description}

During the learning process, to get the complete understanding of the topic the student needs to perform sequence of actions to deal with the wide variety of didactic resources such as course material, examples, exercises, tests, etc. accordingly to their preferences and thinking process. This involves the efforts to develop the course content description through incorporating supportive metadata elements that helps to understand the underlying intellectual knowledge about learning a concept and promotes excellence in learning and thinking process.

Most part of cognition cannot be expressed explicitly, which can be called as experiential knowledge [9], but the most effective way of improving the cognitive skills of the learner on a particular concept or problem, involves providing the learner with conceptual relations, technical requirements, context of the particular learning concept, etc. The psychological and pedagogical approaches to the content modeling can significantly influence the retrieval of potentially usable learning content as per the engagement and investigative behavior of learner.

No one of the existing metadata standards is encompassing all the required metadata elements for every type of application [10]. This requirement has made various organizations to create their own application profile through the assembling of metadata elements selected from one or more metadata schemas and incorporating elements as per their specific needs. Furthermore, to facilitate the search and retrieval of content units based on the semantics of the content, the semantic metadata must be attached to them. 
The cognitive learning style (CLS) defines characteristics of the student learning process [11], In order to model the course content ontology we have considered the mental perspectives of the learner's learning style. Based on student's learning strategies the cognitive learning process dimensions can be comprised into three basic categories; Understanding, Applying and Analyzing as shown in Figure 2. Each of these stages can be further categorized into sub-processes that provide the details of pedagogical support resources required by the learner. The proposed model assumes cognitive learning as a cyclic process.

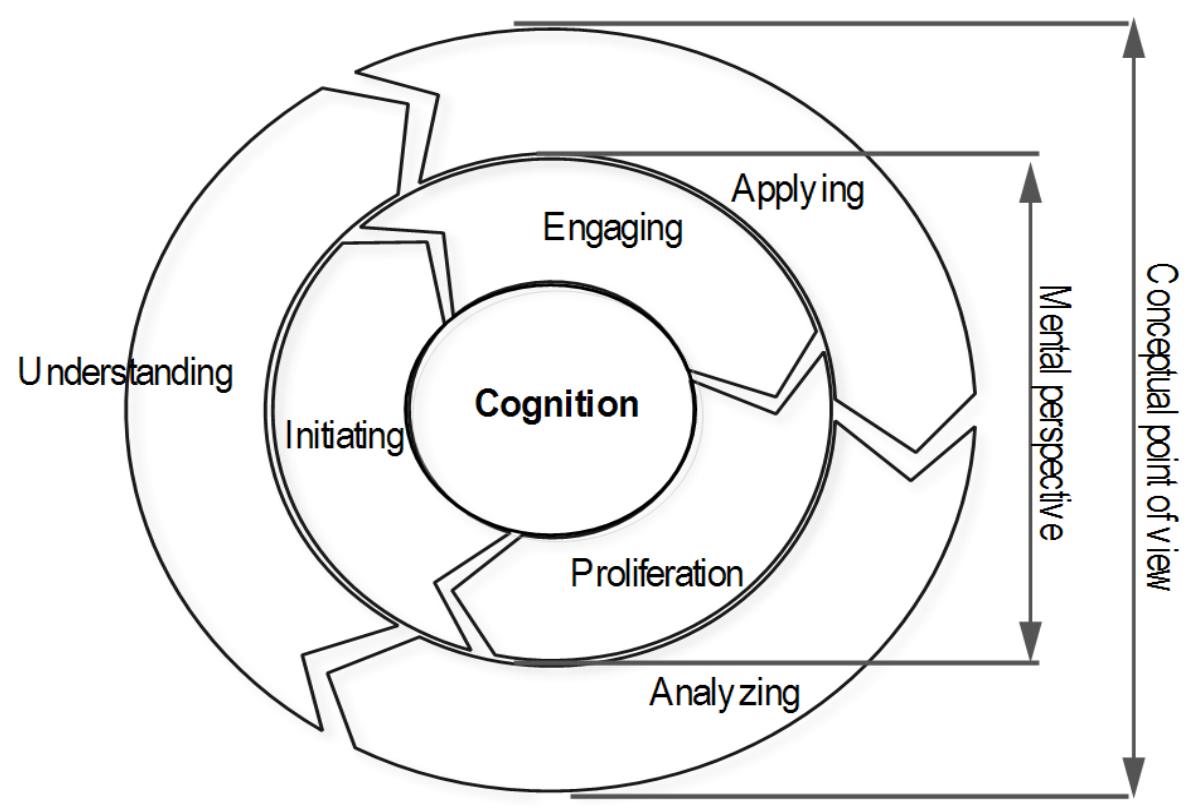

Fig. 2. Conceptual and mental perspectives of cognitive learning process

The courseware development process is the composition of the sequence of learning resources that are adapted to the particular educational context and scenario. As per the course curriculum, the course designer put together a course of topics provided that there is a content repository with meta-information on each of the topics required in the course. The expressive power of the ontology allows us to encode different relations among various concepts.

\section{Ontological Framework}

This section presents an ontology-based conceptual framework to organize the learning resources for cognitive learning environments. The proposed content model 
simplifies student's knowledge-building activities. The ontological approach for description of learning contents improves the search precision through exploiting the various properties and contextual details of learning resources. An ontology is defined as a "formal and explicit specification of a shared conceptualization" [12]. It is a machine understandable format consisting of entities, attributes, and relationships. Ontologies enable creating semantic relationships between various learning objects. For effective managing and intelligent access to learning resources, the semantic based representation has great potential. It allows the search process to filter resources for their intelligent discovery and to facilitate fast access to relevant learning resources.

As proposed by [13] the pool, of course concepts is connected to form a hierarchy where items are likely to be related in two or more differing ways and Knolmayer, G. F. [14] quoted that the composition of course, needs to understand the dependencies between the learning contents.

The proposed conceptual model facilitates the learning environment that provides a higher level of abstraction in the description of course contents. Based on the discussions in the previous sections, we proposed the course content model with some important class and relations, for effective and self-regulated learning process.

The central piece of course content description model is the "Concept" class. To support the cognitive skill development process, the complementary materials with different types of relations among various course concepts are helpful to enhance the Understandability, Applicability and Analysis ability of learner. These three categories of pedagogical support, with base classes and concerned properties are as discussed below.

Understandability: (Concept.hasDescription and Concept.hasExplination ) It is an initial appraisal of the learning process, the details of a concept such as Similar concepts, Prerequisites, Background, etc., must be known before getting excellence on the concept. The additional explanation of concept eventually accompanied with an introduction, Summary, etc. These factors can influence the learner to improve the understandability and motivates the learning process.

Applicability: (Concept.hasApplicability and Concept.hasInteractivity) the learner tries to develop knowledge on the applicability of concept through understanding various properties, behavior, context of the application, etc. To verify the acquired knowledge, the learner attempts to solve the exercises and real world problems.

Analysis: (Concept.isSupportedBy) to get conclusions and to analyze the learned concept, the student has to involve and verify the supporting details such as Facts and Proofs of intended topic.

The ontological representation of the proposed Cognitive Resource Description Metadata with Core Classes and Relations is as shown in Figure 3, which helps for structuring course contents to improve the understanding level and cognitive skills of the learner. 


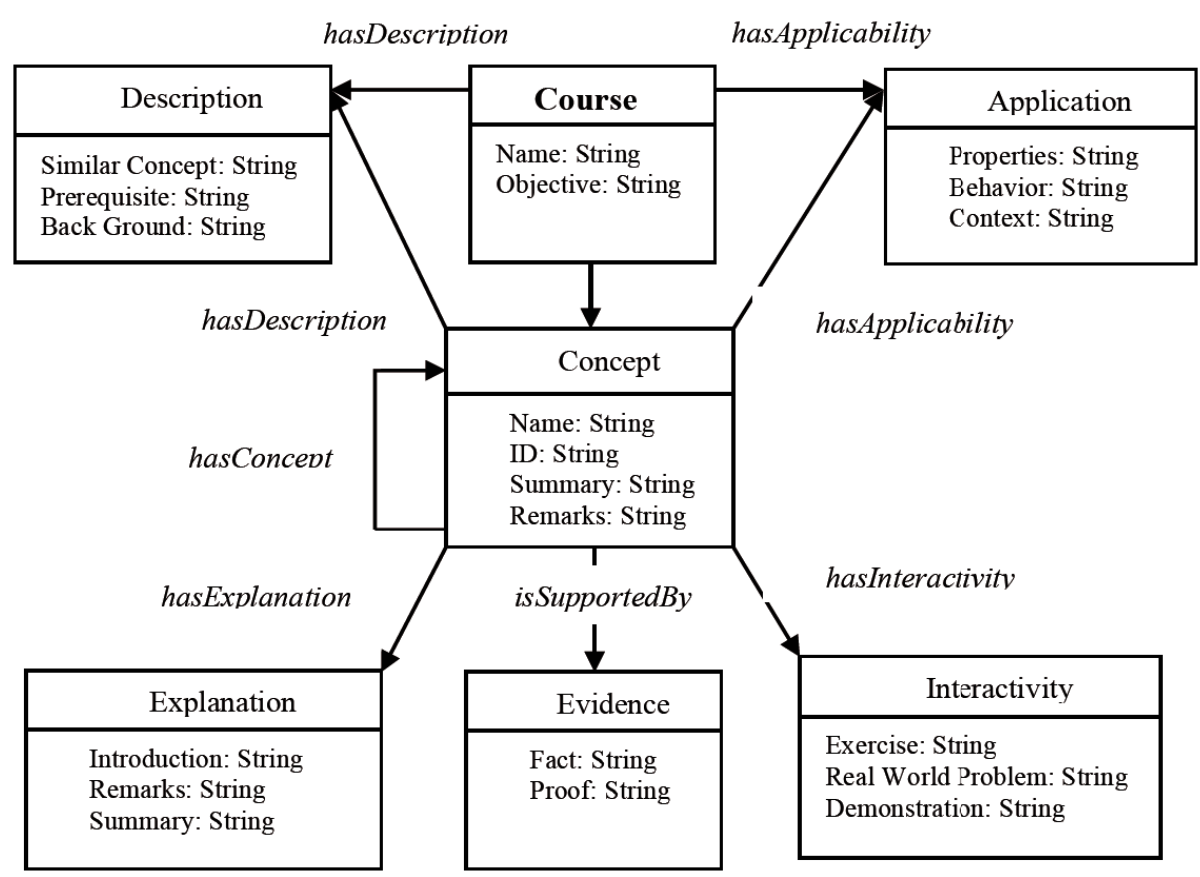

Fig. 3. Core classes and relations of courseware content structure ontology

\section{Conclusion}

This paper described an in-progress research work on integrating pedagogical approach and cognitive based content presentation for web-based learning environments. Here, we discussed some of the important issues in a cognitive learning environment and proposed an ontology based content modeling paradigm that provides the learning environment to improve the cognitive skills of the learner. The added value of the proposed ontology lies in the representation of relations among concepts that enhances the student's thinking process and it provides the means for commonlyobserved difficulties that the learner experiences while using we based learning system. The proposed approach makes the learner to get better insight into the topic and the related ones. In the near future, we plan to extend this proposed work with suitably demonstrated application as a proof of concept; the prototype is to be implemented to provide cognitive based delivery of the learning material to the end user.

\section{$7 \quad$ References}

[1] Panagiotopoulos, I., Kalou, A., Pierrakeas, C., \& Kameas, A. (2012). An Ontological Approach for Domain Knowledge Modeling and Management in E-Learning Systems. In Artificial Intelligence Applications and Innovations (pp. 95-104). Springer Berlin Heidelberg. https://doi.org/10.1007/978-3-642-33412-2 10 
[2] Kalla. Madhu Sudhana, V. Cyril Raj and T.Ravi. (2013). An Architectural-model for Context aware Adaptive Delivery of Learning Material. International Journal of Advanced Computer Science and Applications(IJACSA). 4(10).

[3] Akbulut, Y., \& Cardak, C. S. (2012). Adaptive educational hypermedia accommodating learning styles: A content analysis of publications from 2000 to 2011. Computers \& Education, 58(2), 835-842. https://doi.org/10.1016/j.compedu.2011.10.008

[4] Sweller, J., Van Merrienboer, J. J., \& Paas, F. G. (1998). Cognitive architecture and instructional design. Educational psychology review, 10(3), 251-296. https://doi.org/10.1023/A:1022193728205

[5] Kinley, K., Tjondronegoro, D., Partridge, H., \& Edwards, S. (2012, November). Humancomputer interaction: the impact of users' cognitive styles on query reformulation behaviour during web searching. In Proceedings of the 24th Australian Computer-Human Interaction Conference (pp. 299-307). ACM. https://doi.org/10.1145/2414536.2414586

[6] Bloom, B. S. (1956). Taxonomy of Educational Objectives. Vol. 1: Cognitive Domain. New York: McKay Co. Inc.

[7] Sathiyamurthy, K., \& Geetha, T. V. (2012). Automatic Organization and Generation of Presentation Slides for E-Learning. International Journal of Distance Education Technologies (IJDET), 10(3), 35-52. https://doi.org/10.4018/jdet.2012070103

[8] Froyd, J., \& Simpson, N. (2008, August). Student-centered learning addressing faculty questions about student centered learning. In Course, Curriculum, Labor, and Improvement Conference, Washington DC, 30 (11).

[9] Zhao, D., Xie, C., Sun, X., \& Wang, L. (2011). A Courseware Developing Model Based on Knowledge Modeling. In Advances in Computer Science, Environment, Ecoinformatics, and Education (pp. 274-278). Springer Berlin Heidelberg. https://doi.org/10.1007/9783-642-23339-5 50

[10] Manouselis, N., Salokhe, G., \& Keizer, J. (2009). Comparing different metadata application profiles for agricultural learning repositories. In Metadata and Semantics (pp. 469479). Springer US. https://doi.org/10.1007/978-0-387-77745-0 46

[11] Dutta, B., Madalli, P. and Prasda, A. R. D. (2009). Ontology supported personalized eLearning repositories. In Proceedings of International Conference on Semantic Web and Digital Libraries (ICSD), 10-11 Sep. 2009, Trento, Italy, pp. 193-206.

[12] Gruber, T. R. (1995). Toward principles for the design of ontologies used for knowledge sharing?. International journal of human-computer studies, 43(5), 907-928. https://doi.org/10.1006/ijhc.1995.1081

[13] Brusilovsky, P., \& Vassileva, J. (2003). Course sequencing techniques for large-scale webbased education. International Journal of Continuing Engineering Education and Life Long Learning, 13(1-2), 75-94. https://doi.org/10.1504/IJCEELL.2003.002154

[14] Knolmayer, G. F. (2003, January). Decision support models for composing and navigating through e-learning objects. In System Sciences, 2003. Proceedings of the 36th Annual Hawaii International Conference on (pp. 10-pp). IEEE. https://doi.org/10.1109/hicss. 2003.1173694

\section{Author}

Kalla. Madhusudhana is Professor at the Department of CSE, Teegala Krishna Reddy Engineering College, Hyderabad, India (kallamadhu1@yahoo.com). 